\title{
Communication in legislative bargaining
}

\author{
Andrzej Baranski ${ }^{1}$ John H. Kagel ${ }^{1}$
}

Received: 11 December 2014/Revised: 16 April 2015/Accepted: 23 April 2015/

Published online: 7 May 2015

(C) Economic Science Association 2015

\begin{abstract}
We investigate the Baron-Ferejohn (The American Political Science Review 83(4): 1181-1206, 1989) model of legislative bargaining with cheap talk between the designated proposer and potential coalition partners. Communication results in substantially increased proposer power close to the stationary subgame perfect equilibrium prediction. This is achieved primarily through voters competing with each other to get the proposer to include them in the winning coalition, while arguing for a zero allocation for redundant voters. Voters typically follow through on their stated reservation shares, but proposers often fail to partner with voters making excessively low offers, as these are more likely to be reneged on.
\end{abstract}

Keywords Legislative bargaining $\cdot$ Cheap talk $\cdot$ Bargaining styles

JEL Classification C7 - D7 · D8

\section{Introduction}

The Baron-Ferejohn (1989; BF) legislative bargaining model is one of the most popular, if not the most popular, formal model of the legislative bargaining process. It has been explored experimentally under a variety of different specifications including variations in the size of the committee, in voting rules, whether proposals can be amended, and a number of other variations (see Palfrey 2015 in press, for a

Electronic supplementary material The online version of this article (doi:10.1007/s40881-015-0011-5) contains supplementary material, which is available to authorized users.

John H. Kagel

kagel.4@osu.edu

1 Ohio State University, Columbus, USA 
review). These experiments provide clear qualitative support for the BF model in that minimum winning coalitions (MWC) are quite common, proposals typically pass without delay, and proposers exercise some power achieving higher payoffs than other members of the winning coalition. However, proposer power is substantially weaker than the stationary sub-game perfect equilibrium (SSPE) predicts.

One central element of the legislative bargaining process as it occurs outside the lab, but has been largely missing in these experiments, is pre-play communication between proposers and voters. Under the standard bargaining model, there is no need for pre-play communication; it is assumed that risk neutral players can compute the continuation value of the game, and the only thing that matters is own income. However, past experiments have shown considerable heterogeneity in the payoffs individual players require to secure their vote, so proposers cannot identify voters with the lowest reservation values as coalition partners. ${ }^{1}$ As such, at a minimum, what communication can do is to permit potential coalition partners to signal acceptable offers and, in the case of multilateral bargaining, permit proposers to take advantage of competition between potential coalition partners to elicit their lowest acceptable offers.

Of course, given that pre-play communication is not binding, it is possible that coalition partners will exaggerate their lowest acceptable shares. Alternatively, if the cost of delay is not too high, voters might state very low reservation values with the idea of voting against the proposed allocation and getting a better deal, or having the chance to become the proposer when the bargaining continues. In addition, there is some evidence from bilateral bargaining games (Rankin 2003) and the dictator games (Andreoni and Rao 2011) that communication results in more equal payoffs between bargainers compared to the no communication case. Our game involves three player groups with $\$ 30$ to be distributed under majority rule and no discounting of payoffs following a rejected proposal. The first question addressed is whether permitting free form communication increases proposer power relative to the no communication case. The unambiguous answer is that it results in a substantial increase, with proposers' earnings averaging $63.7 \%$ of the available money in the last five bargaining rounds compared to $66.7 \%$ predicted under the SSPE, and $48.3 \%$ for the no communication control treatment. This significant increase in proposer power is achieved with a slight increase in the frequency with which initial proposals are accepted, consistent with increased voter acceptability of the sharp increase in proposer power with communication.

The second question posed is: What is the mechanism underlying this increase in proposer power? For this, we look at the dialogues between proposers and potential coalition partners. Three bargaining styles are identified: (1) Proposers actively solicit voters' lowest acceptable offers to get them to compete to be included in an MWC (strong proposer bargaining; $29.4 \%$ ), (2) Proposers bargain with potential coalition partners within the context of achieving an "equitable" allocation between

\footnotetext{
1 In past experiments, the payoff needed to get the average voter to be indifferent between accepting or rejecting a proposal is very close to the continuation value of the game (Fréchette et al. 2005b). However, there is substantial heterogeneity in voters reservation values.
} 
all three players (weak proposer bargaining; $7.1 \%$ ), and (3) Potential coalition partners initiate the bargaining, making offers to proposers while frequently calling for a zero allocation for the redundant voter (voters initiated bargaining; $50.6 \%$ ). We also compare potential coalition partners' reservation shares to what they were allocated and the extent to which they renege on these commitments. Here, it is not unusual for proposers to reject rock bottom shares, with voters offering to accept significantly lower shares, more likely to renege on these low offers, compared to somewhat higher offers. Further, it is not uncommon for proposers to offer shares a little above what was requested, which significantly increases the probability that their proposal will be accepted.

The experiment that is closest to ours is Agranov and Tergiman (2014) who also investigate the $\mathrm{BF}$ model with nonbinding communication. There are a number of potentially important differences in our experimental design and theirs. ${ }^{2}$ Our main experimental treatment involves "closed door" bargaining with bilateral communication between proposers and their potential coalition partners, with no communication permitted between voters (think of secret legislative negotiations). In contrast, Agranov and Tergiman permit communication between potential coalition partners, as well as public communication between all players, which is more akin to a double auction market, with strong downward pressure on shares toward the equilibrium outcome. Of potentially more importance, in their experiment the money to be allocated shrinks by twenty percent following rejected offers, which puts strong pressure on accepting lower shares, thereby enhancing proposer power, as well as discouraging voters from forming blocking coalitions in an effort to obtain a better outcome. Finally, our experiment involved three bargainers, theirs five, so that it would be somewhat easier to coordinate the formation of a blocking coalition in our design.

In spite of these differences in experimental design, both yield the same main result: permitting cheap talk into the Baron-Ferejohn legislative bargaining process substantially increases proposer power. However, there is an even greater increase in proposer power in our experiment than in theirs. Motivated by these minor differences we conducted a second, "open door", communication treatment, the same in all respects to our closed door treatment, but with their open door communication. This too results in a sharp increase in proposer power compared to the no communication control, albeit with a somewhat weaker increase in proposer power compared to closed door communication. The results of this treatment are briefly discussed in the results section, with details provided online (Online Supplementary Material).

\section{Experimental design and procedures}

We consider a three-player game where any majority coalition (two out of three) can decide how they should share $\$ 30$ under BF legislative bargaining. In each bargaining round, a proposer is randomly chosen to determine how to share the

\footnotetext{
${ }^{2}$ Our experiment had been well under way prior to learning about theirs.
} 
money. Proposals are voted up or down without any opportunity for amendment. If a proposal passes, the bargaining round ends. If it is rejected, the process repeats itself, with a new randomly determined proposer dividing the $\$ 30$ (no discounting of payoffs). This process repeats itself until a proposed allocation is accepted.

Each bargaining round began with one of the three players designated as offering a proposal to be voted on. ${ }^{3}$ This was followed by a period with free form communication between the proposer and potential coalition partners. After which the proposer submitted a division of the money to be voted on. Under the "closed door" communication protocol only bilateral communication between the proposer and each of the two potential coalition partners was permitted (no opportunity for voters to communicate with each other). The communication period was limited to 3 min, with the proposer having the option to terminate communication unilaterally. The proposer is automatically counted as voting for her proposal making each of the other two voters pivotal. Further, within a given bargaining round player ID numbers are randomly reassigned following a failed proposal. As such there is no opportunity to practice any kind of punishment strategy between stages within a given bargaining round, resulting in a unique subgame perfect equilibrium (SPE). During the communication phase subjects were instructed to remain anonymous, not revealing their names or any other identifying information. ${ }^{4}$

When voting, subjects saw the proposed allocation to all three players, with voting results reported immediately after completion. In case a proposal was rejected, subjects could observe the history of previous proposals.

There were ten bargaining rounds, plus a dry run to familiarize subjects with the software, voting rules and feedback in each experimental session. Subjects were randomly reshuffled into new bargaining groups following the completion of each bargaining round. Earnings are based on the allocation from one randomly selected bargaining round, plus an $\$ 8$ show up fee.

A no communication control treatment was run with exactly the same procedures as with "closed door" communication. There were three closed door communication sessions with between 15 and 18 subjects in each session, along with three no communication sessions with between 12 and 18 subjects in each session. There was no overlap in subject participation between sessions. All participants were Ohio State undergraduate students. Software was developed using z-Tree (Fischbacher 2007).

\section{Theoretical predictions}

The BF model has multiple Nash equilibria, with any accepted proposal constituting an equilibrium. The stationary subgame perfect equilibrium (SSPE) offers a unique prediction, which is essentially a subgame perfect equilibrium (SPE) when players do not exercise any history-based punishment strategies. Given

\footnotetext{
3 This was common knowledge including which of the three was the designated proposer.

${ }^{4}$ Reviewing the conversations, no one violated the anonymity rule. The complete set of instructions is reported in the Online Supplementary Material.
} 
that new IDs were reassigned following rejection of a proposal within a given bargaining round (as well as between bargaining rounds) there was no ability to exercise any history-based punishment strategies, so that there is a unique SPE for the game.

Predictions under the SSPE are that (1) proposers offer MWCs in which one player gets a zero allocation, (2) the remaining voter gets $\$ 10$ (or $\$ 10+\varepsilon$ to break indifference), (3) the proposer keeps $\$ 20$ (or \$20- ), and (4) proposals always pass in stage 1 of each bargaining round. The model assumes risk neutrality so that the continuation value of the game is the weighted average of payoffs under the SSPE$\$ 10 .^{5}$ Risk aversion on the part of voters will result in them accepting lower offers (Harrington 1990), as will other-regarding preferences (Montero 2007). ${ }^{6}$

With communication, messages are non-binding and costless (cheap talk), so that in theory communication has no effect on the bargaining process or the SSPE's predictions. However, if results from sequential bargaining games are guidelines (e.g., the ultimatum game), many players are typically unwilling to accept the extreme payoffs that the SSPE predicts. This creates strategic uncertainty as proposers must trade off proposals with higher own payoffs against the risk that they will be rejected. In this case, cheap talk may be informative, as proposers attempt to identify coalition partners that will permit them to maximize their proposer power. Of course, there is no guarantee promises will be kept. Nevertheless, it is clear that communication can potentially convey private information that otherwise might not be available (Crawford 1998).

More formally, one can envision the bargaining environment as a coordination game where the proposer, absent any social preferences, attempts to maximize the amount kept subject to approval. In doing so, the proposer would like to know the minimum amount that each voter is willing to accept. Similarly, voters would like to receive a positive share and be included in the allocation. Absent communication, there is no mechanism for voters to signal their reservation values in attempts to guarantee a share of the pie. ${ }^{7}$

\footnotetext{
5 The ex ante expected value of the game under the SSPE is obtained solving the equation $v(i)=1 /$ $3 \times 0+1 / 3 \times v(i)+1 / 3(1-v(j))$. The first term is the expected payoff when a member is excluded from the MWC and the second when she is included. The third term is the proposer's expected payoff (by assigning a share $v(j)$ to member $j$ and keeping $1-v(j)$ ). Imposing symmetry, $v(i)=v(j)=v$, and solving the equation yields an expected value of the game of $v=1 / 3$ of the fund, which in our case corresponds to $\$ 10$ being the breakeven point between accepting or rejecting an offer.

${ }^{6}$ A number of alternative explanations have been offered that do rationalize the common failure to achieve the level of proposer power predicted. Fréchette (2009) shows that a learning model in which subjects start out choosing the "obvious" equal division is, with learning, (incompletely) replaced by strategic considerations within an MWC. Nunari and Zapal (2014) show how a model incorporating a combination of imperfect best responses (a QRE model) in conjunction with incorrect beliefs regarding the randomness with which a new proposer will be selected after rejection (a gambler's fallacy) does the trick.

7 We say "attempt" because, if both voters are fully rational, they can correctly anticipate the other voter's offer which would again imply that communication is not effective in guaranteeing a spot in the allocation.
} 
Table 1 Approved allocations closed door bargaining

\begin{tabular}{llllll}
\hline Bargaining rounds & \multicolumn{2}{l}{ Communication } & & \multicolumn{2}{l}{ No communication } \\
& First half & Second half & & First half & Second half \\
\hline Proposer's share $(\$)$ & 16.7 & 19.0 & & 14.4 & 14.6 \\
(Std. errors) & $(0.236)$ & $(0.284)$ & & $(0.155)$ & $(0.138)$ \\
Highest voter share $(\$)$ & 11.4 & 9.6 & & 13.4 & 13.5 \\
(Std. errors) & $(0.272)$ & $(0.281)$ & & $(0.248)$ & $(0.247)$ \\
Approved in Stage 1 $(\%)$ & 87.0 & 80.0 & & 75.0 & 77.5 \\
MWC $(\%)$ & 78.7 & 81.2 & & 72.5 & 76.2 \\
SSPE $\pm 2(\%)$ & 39.5 & 51.8 & & 5.0 & 5.0 \\
\$15-\$15 split $(\%)$ & 16.1 & 3.5 & & 48.8 & 50.0 \\
Equal share for all $(\%)$ & 14.2 & 8.2 & & 10.0 & 8.8 \\
\hline
\end{tabular}

\section{Experimental results}

Table 1 reports key outcomes with and without communication broken out by the first and last five bargaining rounds, where our focus will be on the last five bargaining rounds unless stated otherwise. With communication, the average proposer's share $(\$ 19.00)$ is quite close to the SSPE prediction of \$20. In contrast, proposers' share under the control treatment is just under $\$ 15$, a statistically significant difference $(\mathrm{p}<0.01){ }^{8}$ With communication the frequency of approximate SSPE allocations (SSPE $\pm \$ 2$ ) is $51.8 \%$ versus $5 \%$ without. ${ }^{9}$ In contrast, in the control treatment, $50.0 \%$ of all allocations involve an equal split between the proposer and their coalition partner versus $3.5 \%$ with communication.

Conclusion 1 Closed door communication results in a large, and statistically significant, increase in proposer power compared to no communication, which is only marginally lower than the SSPE prediction. The sharp increase in proposer power with communication does not impact stage 1 acceptance rates, indicative of the acceptability of the increased proposer power.

Figure 1 provides details regarding proposers' shares. Panel A shows that average shares were essentially the same between the two treatments in the first bargaining round. However, proposers' shares increase quite rapidly after that, while remaining relatively flat for the controls. Panel B shows that proposers' shares are compactly distributed around a mean of $\$ 15$ in the control treatment versus a much more diffuse distribution centered on \$18-\$20 with communication.

To understand the mechanism behind this substantial increase in proposer power, two undergraduate students independently coded the records between proposers and

\footnotetext{
8 This is based on a $t$ test using bargaining round as the unit of observation. Using the far more conservative session averages as the unit of observation, the differences are significant at $p=0.05$ using a Mann-Whitney test. Regressions with clustering errors at the session level are significant at the 0.05 level (two-tailed test) and at better than the $1 \%$ level with clustering at the subject level. Results under the control treatment are typical for BF games without communication (see Fréchette et al. 2005a, for example).

9 Forty two percent of the SSPE $\pm \$ 2$ allocations were approved with no delay in the second half.
} 

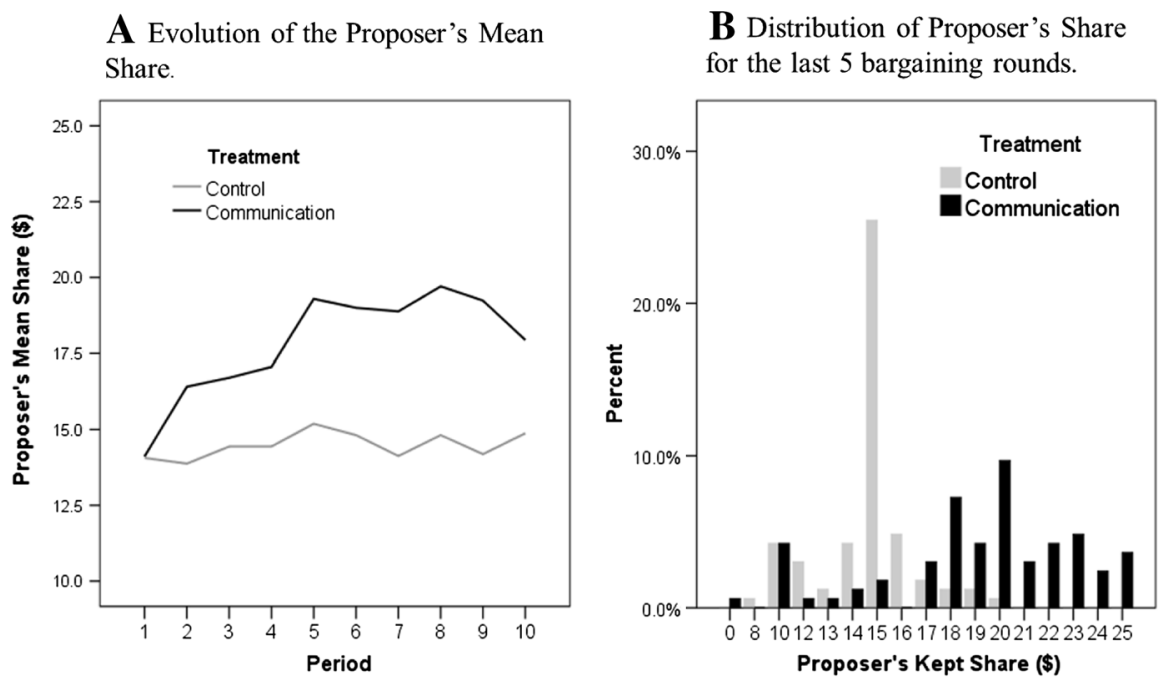

Fig. 1 Evolution and distribution of the proposer share

potential coalition partners. We established the categories to be coded based on a sampling of the records. The students then coded up a single session, after which we met jointly to resolve obvious inconsistencies in interpreting the categories (these were minimal). The students then coded the remaining sessions. The average agreement rate across all categories was $91.2 \%$.

We distinguish between weak and strong proposer bargaining: With "weak proposer bargaining" the proposer negotiates within the context of "payments for all". With "strong proposer bargaining", proposers actively solicit reservation values to generate competition to be included in an MWC. That is, a weak bargainer has a taste for "fairness" (equal payments to all, or a willingness to offer both voters sizable payments), while a strong bargainer does not. With "voter initiated bargaining" voters lead the bargaining process, making offers to a relatively passive proposer. Examples of all three bargaining styles are reported in the Online Supplementary Material. We also coded for cases where one or both of the voters called for a strict MWC (a zero share for the other voter) and, where available, the first and last shares a voter requested or agreed to.

Table 2 shows the frequency of each coding category along with proposers' average shares realized within that category. Voter Initiated bargaining accounts for nearly half of the bargaining styles, and holds steady over time. In contrast, strong proposer bargaining starts low $(14.2 \%)$ but more than doubles between the first and last five bargaining rounds. Proposer's share under strong proposer bargaining stays constant over time at slightly over \$20. Proposer's share under voter initiated bargaining increases substantially over time: It is significantly less than strong proposer bargaining in the first five rounds $(\$ 3.40$ lower, $\mathrm{p}<0.01)$, but is no longer significantly different in the last five rounds $(\$ 1.60$ lower, $p=0.14) .{ }^{10}$ The

\footnotetext{
${ }^{10}$ Both are one-sided t-tests using each coded conversation as the unit of observation.
} 
Table 2 Bargaining styles

\begin{tabular}{llll}
\hline Bargaining style & & \multicolumn{2}{l}{ Bargaining rounds } \\
\cline { 3 - 4 } & & $1-5$ & $6-10$ \\
\hline Strong proposer bargaining & Frequency & $14.20 \%$ & $29.40 \%$ \\
& Mean share kept & $\$ 20.60$ & $\$ 20.80$ \\
& & $(0.55)$ & $(0.377)$ \\
Weak proposer bargaining & Frequency & $18.90 \%$ & $7.10 \%$ \\
& Mean share kept & $\$ 11.60$ & $\$ 15.20$ \\
Voter initiated bargaining & & $(0.449)$ & $(1.208)$ \\
& Frequency & $50.80 \%$ & $50.60 \%$ \\
& Mean share kept & $\$ 17.20$ & $\$ 19.20$ \\
Other & & $(0.155)$ & $(0.36)$ \\
& Frequency & $16.10 \%$ & $12.90 \%$ \\
& Mean share kept & $\$ 17.50$ & $\$ 15.70$ \\
& & $(0.557)$ & $(0.879)$ \\
\hline
\end{tabular}

Standard errors in parentheses. Approved allocations only

frequency of weak proposer bargaining decreases over time, largely being replaced by strong proposer bargaining.

Conclusion 2 Strong proposer bargaining, along with voter initiated bargaining, accounts for $80 \%$ of the approved allocations over the last five bargaining rounds, with voter led bargaining accounting for just over $60 \%$ of this total.

One corollary to the increase in proposer power relative to no communication is an increased frequency of voters calling for a strict MWC (zero payoff to the other voter) typically discussed in the context of increasing the amount of money to be shared with the proposer. This starts out at $50 \%$ in the first bargaining round and quickly increases to $88.2 \%$ in the second bargaining round, staying close to that level until the end. This increase is matched with a large decrease in the frequency of weak proposer bargaining, more than likely because proposers realize they can get a substantially larger share for themselves, or in response to the selfishness of others.

Conclusion 3 Voter initiated bargaining accounts for $50 \%$ of all bargaining styles in the last five bargaining rounds, followed by strong proposer bargaining at $29 \%$. There is a sharp increase with voters calling for a strict MWC in order to have more money to split with the proposer, at well over $80 \%$ by the second bargaining round.

So far, the analysis has focused on approved allocations. Nevertheless, rejected allocations tell an interesting story, particularly given that the communication involved cheap talk. Proposers are clearly wary of accepting the lowest reservation value offered: For all cases where both voters stated a reservation share, when the lowest reservation share was in the interval \$1-\$3 it was almost always rejected in favor of a higher reservation share, with about half of those in the interval $\$ 4-\$ 6$ accepted. Once stated reservation shares were $\$ 7$ or more, they were accepted in the 
overwhelming number of cases, with reservation shares of $\$ 10$ or more essentially always accepted. ${ }^{11}$ Among MWCs, proposers exactly fulfill the stated reservation share $57.3 \%$ of the time, with these proposals rejected $17.4 \%$ of the time. In $29.1 \%$ of MWCs, proposers offer to increase the included voter's reservation share (average increase of $\$ 1.90$ ), with $9.3 \%$ of these proposals rejected. In $13.6 \%$ of MWCs proposers offered less than a voters stated reservation value (average decrease of $\$ 2.20$ ), of which $40 \%$ were rejected. A probit shows that offering a larger share than requested increases the odds of the proposal being accepted by $12.9 \%(\mathrm{p}<0.10)$, while offering a lower share decreases the odds by $32 \%$ $(\mathrm{p}<0.01) .^{12}$

Conclusion 4 Proposers do not always accept the lowest share offered, allocating money to the higher proposed allocation in $43 \%$ of MWCs. Within MWCs, voters reject shares equal to their stated reservation value $17 \%$ of the time, versus $9 \%$ when offered more than their stated reservation value, rejecting $40 \%$ of offers that come in below the requested amount. These differences in rejection rates are statistically significant controlling for the amount offered.

Probits comparing voting with and without communication are reported in Table 3, where the dependent variable is equal to 1 when voting in favor of a proposal. Right hand side variables include a voter's own share (in dollars) for the highest share offered along with the other voter's share as long as it was $\$ 1.00$ or greater. Communication and $\mathrm{MWC}$ are dummy variables equal to 1 with communication and with an MWC, respectively, 0 otherwise. The Communication dummy is interacted with the voter's own share, the other voter's share, and MWC. Voters own share includes only the voter with the largest share, as the remaining voter typically received $\$ 1.00$ or less (effectively being left out of an MWC), which offers were routinely rejected ( $97.1 \%$ of the time). To include shares for all voters would bias the coefficient value for voting when receiving a meaningful share, the variable of primary interest. ${ }^{13}$ Standard errors are clustered at the subject level. Marginal effects are also reported, evaluated at the mean value for the variable in question. We focus on the restricted model which drops other's share and other's share interacted with communication, as neither is statistically significant, nor are they jointly significant $(p=0.72)$. The results largely confirm what has been reported so far.

The coefficient for Communication is positive and statistically significant, reflecting the fact that voters are more willing to accept lower shares with communication. Own Share is positive and statistically significant, as is to be expected. The interaction between Communication and Own Share is negative and

\footnotetext{
11 For $80 \%$ of MWCs in the last five rounds, chat records contained the reservation share for both voters. See Figure A1 in the appendix for the distribution of stated reservation shares and whether they were accepted or not.

12 The probit was run over the last five bargaining rounds (110 observations), including the last dollar amount agreed to plus dummy variables for an increase or decrease in shares offered relative to this. Standard errors are clustered at the individual subject level.

13 There were a couple of cases where the voter receiving the largest share got $\$ 1$ or less. These, too, have been excluded. In cases where equal shares were offered to both voters, both are included in the probit.
} 
Table 3 Voting Probit (standard err. clustered by subject)

\begin{tabular}{|c|c|c|c|c|}
\hline & \multicolumn{2}{|l|}{ Full model } & \multicolumn{2}{|l|}{ Restricted model } \\
\hline & Coef. & $\begin{array}{l}\text { Marginal } \\
\text { effect }\end{array}$ & Coef. & $\begin{array}{l}\text { Marginal } \\
\text { effect }\end{array}$ \\
\hline Communication & $3.485(1.276) * * *$ & 0.796 & $3.693(1.074 * * *$ & 0.825 \\
\hline Own share & $0.486(0.087) * * *$ & 0.133 & $0.488(0.087)^{* * *}$ & 0.135 \\
\hline Other's share & $0.024(0.079)$ & 0.007 & & \\
\hline MWC & $-1.360(0.774)^{*}$ & -0.298 & $-1.569(0.411)^{* * *}$ & -0.321 \\
\hline $\begin{array}{l}\text { Communication own } \\
\text { share* }\end{array}$ & $-0.298(0.101)^{* * *}$ & -0.082 & $-0.286(0.101)^{* * *}$ & -0.079 \\
\hline $\begin{array}{l}\text { Communication other's } \\
\text { share* }\end{array}$ & $0.051(0.127)$ & 0.014 & & \\
\hline Communication MWC* & $1.575(1.043)$ & 0.357 & $1.273(0.544)^{* * *}$ & 0.299 \\
\hline Constant & $-4.541(1.045)^{* * *}$ & & $-4.354(0.919) * * *$ & \\
\hline
\end{tabular}

Vote (dependent variable) is equal to 1 when the subject votes in favor of the proposed allocation and 0 otherwise. Standard errors in parentheses below the coefficient. ***,**, and * denote significance at 1, 5, and $10 \%$ levels respectively. 231 total observations

significant, so that as Own Share increases voting differences in rejection rates between the two treatments tend to disappear. The MWC dummy is negative and statistically significant, but positive and of nearly the same size when interacted with the Communication dummy so that the net effect with communication is effectively zero. ${ }^{14}$ Computing the difference in the probability of voting in favor of a proposal, at the mean value of Own Share with communication (\$10.95), voters are $82.5 \%$ more likely to vote in favor of such a proposal with communication than without. Thus, a proposal approximating the SSPE allocation has little chance of being accepted without communication $(14.8 \%)$, but with communication the same allocation has an $85.6 \%$ chance of being accepted.

\subsection{Open door bargaining}

Motivated by the discovery of the closely related experiment reported in Agranov and Tergiman (2014) two open door bargaining sessions were conducted with 12 and 15 subjects respectively. ${ }^{15}$ Under this treatment the communication protocol permitted private communication between voters as well as broadcasting to all three players. Also, subject ID numbers remained constant within a given bargaining round so that any potential blocking coalition would be able to execute their plans

\footnotetext{
14 The negative sign for MWC in the no communication treatment is, at first blush, puzzling, particularly in conjunction with the total lack of statistical significance for Other's Share. Bradfield and Kagel (2014) show that this results from the fact that shares for the "other" voter are inversely related to the difference in shares between the proposer and the voter getting the largest share in a three player game. This suggests that absent communication, individuals are more sensitive to differences in their payoffs compared to the proposer's payoff.

15 One of these sessions suffered a computer breakdown in bargaining round 9 .
} 
once a proposal was rejected. We report a summary of the results from this treatment, focusing on the development (or lack thereof) of blocking coalitions. Details of the experimental outcomes are reported in the online appendix (Online Supplementary Material).

Proposer power is diluted somewhat compared to closed door communication: average proposers' payoffs with open door of $\$ 17.6$ versus $\$ 19.0$ with closed door bargaining. ${ }^{16}$ Voters communicated privately with each other in efforts to form a blocking coalition in $26.8 \%$ of all bargaining rounds, and in $41.9 \%$ of the last five bargaining rounds. Communication was coded according to whether voters were discussing a weak or a strong deal: A weak deal is defined as one in which voters discuss rejecting a proposal with no specification of how they planned to split the $\$ 30$ after that, a strong deal discussed how to split the $\$ 30$.

Just over $75 \%$ of all voter-to-voter discussions involved strong deals, of which $80.9 \%$ involved planning for an equal split between the two voters following rejection. Of these, $63.2 \%$ failed to materialize as one of the voters accepted the offer at hand (averaging \$12.10). Of the successful rejections of a proposer's offer, two failed when the same proposer was selected in the second stage of the bargaining round. In the remaining five cases voters carried out their plan for an equal split after rejection. Only one of the five weak deals was successful in blocking a proposal. There are many reasons why blocking coalitions were not more successful, including the fact that, in $77.5 \%$ of all negotiations, at least one voter suggests a strict MWC to the proposer.

Conclusion 5 Open communication reduced proposer power somewhat over the last five bargaining rounds compared to closed door communication from $95 \%$ of the SSPE to $88 \%$. Efforts at blocking coalitions were only mildly successful, as the majority collapsed in the face of reasonable positive offers to one of the voters.

\section{Summary and conclusions}

We report an experimental investigation of the Baron-Ferejohn (1989) legislative bargaining model with cheap talk. Although standard game theoretic modeling assumptions imply that cheap talk is irrelevant to the outcome of the game, given the strategic uncertainty proposers' face between obtaining a more favorable proposal against the risk of having their proposal rejected, cheap talk helps to resolve some of this strategic uncertainty. Proposers obtain larger shares, significantly closer to the SSPE outcome, without any reduction in the frequency with which stage one offers are rejected. Proposers are not naïve with respect to cheap talk, as they often do not include the voter with the lowest reservation value as these are, on average, well below the continuation value of the game and quite likely to be rejected. This experimental design brings the laboratory game closer to

\footnotetext{
16 A standard $t$ test using the average each proposer's share as the unit of observation yields a significant difference at the $10 \%$ level (one-tailed test). Regressions with clustering at the session level fail to achieve statistical significance at conventional levels $(\mathrm{p}=0.40$, two-tailed test $)$ but do with clustering at the subject level ( $\mathrm{p}=0.09$, two tailed test). See Agranov and Tergiman (2015) for comparisons of open versus closed door bargaining within in their five player games.
} 
the target application, in that legislative bargaining outside the lab typically involves a considerable amount of pre-proposal, and quite often, private communication between agents.

The experiment also provides a number of related insights: Negotiations under closed door communication are dominated by voter initiated efforts to get into a strict minimum winning coalition, with one or both voters calling for excluding the "other" member. With open communication, blocking coalitions are hard to form, even under very favorable conditions, as voters' defect in favor of a decent offer. Taken as a whole, our results, in conjunction with the results reported in Agranov and Tergiman (2014) show the robustness of cheap talk on increasing proposer power within the Baron-Ferejohn legislative bargaining game.

Part of our motivation for introducing communication in the BF game was to bring the lab closer to field settings, where there is invariably pre-play communication and bargaining before proposals are voted on. From this perspective, there is still a lot left out of the model. First, there are repeated play interactions in field settings versus the one shot nature of the bargaining process reported on here. Repeated play might serve to soften the bargaining process, as well as make breaking voting commitments more costly. Second, our bargainers have no ideological commitments or public policy interests at stake which are likely to be present in field settings. ${ }^{17}$ No doubt, the reader can think of more differences that might impact bargaining outcomes. These remain to be explored in future research.

Acknowledgments This research was partially supported by NSF Grant SES-1226460. We have benefited from comments of participants at seminars in Mannheim University, Maastricht University, CREED at Amsterdam University, Ohio State University, and from participants at the small scale conference on political economy at Cal Tech in the Spring of 2013, the ESA North American meetings in Santa Cruz, and the Political Economy Workshop in Sacro Cuore 2014. The usual caveat applies.

\section{References}

Agranov, M., \& Tergiman, C. (2014). Communication in Multilateral Bargaining. Journal of Public Economics, 118, 75-85.

Agranov, M., Tergiman, C. (2015). Transparency versus Backroom Deals in Bargaining. Unpublished manuscript.

Andreoni, J., \& Rao, J. M. (2011). The power of asking: how communication affects selfishness, empathy, and altruism. Journal of Public Economics, 95(7), 513-520.

Baron, D. P., \& Ferejohn, J. A. (1989). Bargaining in legislatures. The American Political Science Review, 83(4), 1181-1206.

Bradfield, A. J., Kagel, J.H. (2014). Legislative Bargaining with Teams. Unpublished manuscript.

Christiansen, N, Georganas, S., Kagel, J.H. (2013). Coalition Formation in a Legislative Voting Game. AEJ: Microeconomics, 6(1), 182-204.

Crawford, Vincent P. (1998). A survey of experiments on communication via cheap talk. Journal of Economic Theory, 78, 286-298.

Fischbacher, U. (2007). z-Tree: Zurich Toolbox for Ready-made Economic experiments. Experimental Economics, 10(2), 171-178.

17 See Christiansen et al. (2013) for a step in this direction. 
Fréchette, G. (2009). Learning in a multilateral bargaining experiment. Journal of Econometrics, 153, $183-195$.

Fréchette, G., Kagel, J. H., \& Morelli, M. (2005a). Nominal bargaining power, selection protocol, and discounting in legislative bargaining. Journal of Public Economics, 89(8), 1497-1517.

Fréchette, G. R., Kagel, J. H., \& Morelli, M. (2005b). Behavioral identification in coalition bargaining: an experimental analysis of demand bargaining and alternating offers. Econometrica, 73(6), 1893-1938.

Harrington, Joseph. (1990). The role of risk preferences in bargaining when acceptance of a proposal requires less than unanimous approval. Journal of Risk and Uncertainty, 3(June), 135-154.

Montero, Maria. (2007). Inequity aversion may increase inequity. Economic Journal, 117(519), $192-204$.

Nunnari, S., Zapal, J. (2014). Gambler's fallacy and imperfect best response in legislative bargaining. Unpublished manuscript.

Palfrey, T.R. (2015). Experiments in Political Economy. Handbook of Experimental Economics, Vol. 2. In J. H. Kagel, A. E. Roth (Eds.). Princeton University Press (in press).

Rankin, F. W. (2003). Communication in ultimatum games. Economics Letters, 81(2), 267-271. 